Tohoku J. Exp. Med., 2008, 214, 89-96

\title{
Altered Biochemical Parameters in the Saliva of Patients with Breast Cancer
}

\author{
Ebru Emekli-Alturfan, ${ }^{1}$ Gokhan Demir,${ }^{2}$ Emel Kasikci, ${ }^{1}$ Tugba Tunali-Akbay, ${ }^{1}$ \\ Rabia Pisiriciler, ${ }^{3}$ Esin CALISKan ${ }^{3}$ and Aysen Yarat ${ }^{1}$ \\ ${ }^{1}$ Department of Biochemistry, Marmara University, Faculty of Dentistry, Nisantasi, Istanbul, \\ Turkey \\ ${ }^{2}$ Department of Medical Oncology, Istanbul University, Cerrahpasa Medical Faculty, Cerrahpasa, \\ Istanbul, Turkey \\ ${ }^{3}$ Department of Histology and Embryology, Marmara University, Faculty of Dentistry, Nisantasi, \\ Istanbul, Turkey
}

Saliva plays an important role in the protection of oral cavity and alterations in either salivary flow rate or protein composition may have dramatic effects on oral health. Prevention and management of oral complications of cancer and cancer therapy will improve oral function and quality of life, and reduce morbidity and the cost of care. The aim of this study was to investigate the saliva of patients with breast cancer biochemically and cytologically and compare with healthy controls. Accordingly, lipid peroxidation (LPO), total protein, salivary flow rate, and $\mathrm{pH}$ levels were measured in the saliva samples obtained from 20 breast cancer patients and 11 healthy individuals. Tissue factor (TF) is a major regulator of normal hemostasis and thrombosis, and TF activity of saliva samples was evaluated. Under the conditions used, patients with breast cancer present a significant reduction in total protein, $\mathrm{pH}$ and LPO levels. Salivary TF activity was higher in breast cancer patients than that in control subjects, but the degree of increase was not statistically significant. In addition, the analysis of saliva samples by SDS polyacrylamide gel electrophoresis showed the retarded mobility of the 66-kDa proteins and the increased proteins of about $36 \mathrm{kDa}$ in the patient group. Some patients with breast cancer had increased number of leucocytes. Importantly, dysplastic cells and yeast cells were detected only in saliva samples of cancer patients. Decreased salivary LPO may be considered as a risk factor for breast cancer. - breast cancer; saliva; tissue factor; lipid peroxidation; protein.

Tohoku J. Exp. Med., 2008, 214 (2), 89-96.

(C) 2008 Tohoku University Medical Press

Cancer is a leading cause of death worldwide and breast cancer is the fifth most common cause of cancer death (after lung cancer, stomach cancer, liver cancer, and colon cancer). On the other hand, among women worldwide, breast cancer is the most common cancer and the most common cause of cancer death (WHO 2006).
Saliva plays an important role in the protection of oral cavity and alterations in either salivary flow rate or protein composition may have dramatic effects on oral health (Dawes 1996). Cancer and cancer therapy induces multiple oral complications, including mucositis, oropharyngeal pain, hyposalivation, mucosal infection,

Received September 4, 2007; revision accepted for publication December 10, 2007.

Correspondence: Ebru Emekli-Alturfan, Ph.D., Marmara University, Faculty of Dentistry, Department of Basic Sciences, Nisantasi, 34365, Istanbul, Turkey.

e-mail: ebruemekli@yahoo.com,ayarat@marmara.edu.tr 
exacerbation of dental or periodontal disease, caries or demineralization risk, gingivitis and taste disturbance. Therefore, prevention and management of oral complications of cancer and cancer therapy will improve oral function and quality of life, and reduce morbidity and the cost of care. Oral assessment, and oral and dental care have been strongly recommended before cancer therapy and should be continued during and after cancer therapy (National Institutes of Health Consensus Development Conference on Oral Complications of Cancer Therapies 1990; Epstein et al. 2001; Miller et al. 2001; Sonis et al. 2001).

Tissue factor (TF), also known as thromboplastin or Factor III, is considered to be a major regulator of normal hemostasis and thrombosis (Nemerson 1995; Marutsuka et al. 2005). TF is an essential initiator of the coagulation cascade and is expressed during various stages of atherosclerotic lesions (Marutsuka et al. 2005). Together with the proteolytic enzyme factor VIIa, TF sequentially activates factor $\mathrm{X}$ and prothrombin, leading to fibrin deposition and formation of a blood clot. Although the role of TF in coagulation-unrelated events such as inflammation, sepsis, and angiogenesis is extensively investigated, the role of TF in tumor invasion and metastasis has undoubtedly attracted most attention because of its obvious clinical relevance (Versteeg et al. 2004). Various tissues and body fluids (amniotic fluid, bile, semen, sweat, or tears) have been known to have TF activity (Zacharski 1979; Price et al. 2004; Yarat et al. 2004; Alturfan et al. 2006; Emekli-Alturfan 2007). However, most of them are not easily obtained, saliva, on the other hand, is especially suitable for study because of its ready availability.

Diagnosis of disease via the analysis of saliva is potentially valuable since collection of the fluid is associated with fewer compliance problems as compared with the collection of blood. Moreover, the use of a saliva-based test could prove very useful in post-operative and/or adjunctive therapy management of breast cancer patients (Bigler et al. 2002). To our knowledge, there is no study in the literature investigating salivary TF activity in breast cancer patients. Since TF is expressed in a wide range of cancer cells and plays important roles in cancer progression and metastasis (Ueno et al. 2000), we hypothesized that salivary TF activity may also change in breast cancer patients and this may contribute to the oral complications. Therefore the aim of this study was to evaluate TF activity, $\mathrm{pH}$, salivary flow rate, total protein of saliva samples obtained from breast cancer patients and healthy individuals. Moreover, saliva imprint samples were evaluated cytologically. In addition since saliva is reported to be suitable to detect the body's oxidative stress level (Arana et al. 2006), lipid peroxidation (LPO) levels were determined in saliva samples. Saliva samples were also examined electrophoretically.

\section{Materials and Methods}

\section{Saliva}

Included in this study were 20 breast cancer patients with average age of 52 years with varying histological diagnoses. Samples were taken during chemotherapy application and chemotherapy was designed in adjuvant, neoadjuvant and palliative settings. General characteristics of the patients and drugs included in chemotherapy combinations are given in Table 1. The control group consisted of 11 healthy women with average age of 45 years having no systemic disease or history of breast cancer. Breast cancer patients were selected from individuals who attended Istanbul University Medical Faculty Oncology Department and control subjects from Marmara University, Faculty of Dentistry. Saliva samples were collected in restful and quiet circumstances. All subjects gave informed consent to participate in the study. Unstimulated mixed saliva samples were collected, after overnight fasting, before breakfast, at the time interval 08:00-10:00, and after the mouth had been rinsed with distilled water, by spitting into a funnel. Saliva volume and collection time were recorded to calculate salivary flow rate. Saliva samples were centrifuged (3,000 rpm for $5 \mathrm{~min}$ ) and LPO and total protein concentrations were determined in the supernatant. On the other hand, saliva samples were not centrifuged for TF activity and cytological examinations but they were vortexed at least $10 \mathrm{sec}$ for easy sampling. Saliva samples were analyzed for $\mathrm{pH}$ by using $\mathrm{pH}$ paper (Neutralit $\mathrm{pH}$ 5.5-9.0, with graduation 0.5 Merck-pH Indikatepapier). 
TABLE 1. Characteristics of patients with breast cancer and control groups.

\begin{tabular}{|c|c|c|c|c|c|c|c|}
\hline \multicolumn{8}{|c|}{ Breast cancer group $(n=20)($ mean age $=52)$} \\
\hline $\mathrm{P} 1$ & $\mathbf{a} \mathbf{\square} \bigcirc$ & P6 & c 口ם & P11 & $\mathbf{c} \mathbf{\square}$ & P16 & $\mathbf{g} \diamond \mathbf{D} \bigcirc$ \\
\hline $\mathrm{P} 2$ & $\mathbf{b} \mathbf{\square}$ & $\mathrm{P} 7$ & $\mathbf{d} \boldsymbol{\square} \bigcirc$ & $\mathrm{P} 12$ & $\mathbf{c} \mathbf{\square}$ & P17 & $\mathbf{a} \mathbf{\square}$ \\
\hline P3 & $\mathbf{c} \boldsymbol{\square} \boldsymbol{\nabla} \bigcirc$ & P8 & $\mathbf{c} \boldsymbol{\square} \bigcirc$ & $\mathrm{P} 13$ & $\mathbf{a} \mathbf{a}$ & P18 & $\mathbf{g} \bigcirc \diamond$ \\
\hline $\mathrm{P} 4$ & a $\mathbf{0}$ & $\mathrm{P9}$ & e & P14 & $f \mathbf{r}$ & P19 & h $\mathbf{\square}$ \\
\hline P5 & a & $\mathrm{P} 10$ & b $\diamond$ & P15 & $\mathbf{a} \mathbf{\diamond} \bigcirc$ & $\mathrm{P} 20$ & $\mathbf{i} \diamond$ \\
\hline \multicolumn{8}{|c|}{ Control group $(n=20)($ mean age $=45)$} \\
\hline $\mathrm{C} 1$ & - & $\mathrm{C} 4$ & D & $\mathrm{C} 7$ & $\mathbf{0} \mathbf{\square}$ & $\mathrm{C} 10$ & $\square$ \\
\hline $\mathrm{C} 2$ & $\boldsymbol{\square} \bigcirc$ & $\mathrm{C} 5$ & D & $\mathrm{C} 8$ & - & $\mathrm{C} 11$ & $\boldsymbol{\square} \bigcirc$ \\
\hline $\mathrm{C} 3$ & $\mathbf{D} \bigcirc$ & C6 & $\square$ & C9 & $\square$ & & \\
\hline
\end{tabular}

$\mathrm{C}$ and $\mathrm{P}$ represent control group and patient group respectively; the numbers represent the subjects in the group. Letters (a-i) represent drugs included in chemotherapy combinations.

a: Cyclophosphamide-Epirubicin-Fluorouracil, 5-FU b: Cylophosphamide- Fluorouracil, 5-FU c: Docetaxel-Trastuzumab d: Docetaxel e: Anastrozole-Zoledronic acid f: Capecitabine g: Cyclophosphamide-Methotrexate- Fluorouracil, 5-FU h: Capecitabine-Zoledronic acid-Trastuzumab i: Carboplatin-Docetaxel-Trastuzumab; $\mathbf{\square}$ : wearing dentures; $\mathbf{D}$ : having dental caries; $\diamond$ : having cancer heredity in the family; $\bigcirc$ : having periodontal disease

\section{Assay of tissue factor activity}

Tissue factor activities of saliva samples were determined according to Quick's one stage method (Ingram and Hills 1976) using normal plasma. This was performed by mixing $0.1 \mathrm{ml}$ saliva with $0.1 \mathrm{ml}$ of $0.02 \mathrm{M}$ $\mathrm{CaCl}_{2}$, with the clotting reaction being started on addition of $0.1 \mathrm{ml}$ of plasma. All reagents were brought to the reaction temperature $\left(37^{\circ} \mathrm{C}\right)$ before admixture. Since the clotting time is inversely proportional to the tissue factor activity, the lengthening of the clotting time is a manifestation of decreased TF activity.

\section{Biochemical assays}

Total protein content of saliva samples were evaluated by the method of Lowry (Lowry et al. 1951). LPO was assayed by measuring malondialdehyde (MDA) levels in saliva. MDA levels in saliva were determined as thiobarbituric acid reactive substances (TBARS) according to the method of Yagi (1984). Electrophoretic examination of saliva proteins was carried out by Laemmli SDS-polyacrylamide gel electrophoresis (Laemmli 1970).

\section{Cytological examinations}

For cytological examinations saliva samples were smeared over a glass microscope slide and fixed with air. Then they were stained with Giemsa stain and micro- scopically examined for the presence of epithelial cells, leucocytes, bacteria, and dyplastic and yeast cells (Atay and Topalidis 1994).

\section{Statistical analysis}

Data are presented as mean \pm standard deviation. The differences between the values of the groups were tested by Student $t$-test and Wilcoxon signed-rank test. Differences with $p$ values of 0.05 or less were considered significant. Statistical analysis was performed with the SPSS software for Windows, Version 11.

\section{Results}

Total protein, LPO levels and $\mathrm{pH}$ values of breast cancer patients were significantly lower than those of healthy controls $(p<0.05)$. No significant differences were observed between salivary flow rates of breast cancer patients and the healthy controls. Salivary TF activity was higher in breast cancer patients than that in the control group, but the difference was not statistically significant (Table 2).

No significant differences were found between breast cancer patients and healthy controls regarding epithelial cells, leucocytes, bacteria, dysplastic cells and yeast cells (Table 3 ). The 
TABLE 2. Salivary flow rate, $\mathrm{pH}$, protein, tissue factor activity and lipid peroxidation levels in breast cancer patients $(n=20)$ and control group $(n=11)$.

\begin{tabular}{lcc}
\hline & Control group & Breast cancer group \\
\hline Salivary flow rate $\left(\mathrm{ml} \mathrm{min}^{-1}\right)$ & $0.52 \pm 0.38$ & $0.57 \pm 0.53$ \\
Salivary $\mathrm{pH}$ & $7.4 \pm 0.44$ & $6.7 \pm 0.8^{*}$ \\
Saliva total protein $\left(\mathrm{mg} \mathrm{ml}^{-1}\right)$ & $324.9 \pm 46.35$ & $264.6 \pm 73.29 *$ \\
Salivary tissue factor activity $(\mathrm{sec})$ & $68.55 \pm 22.1$ & $59.5 \pm 20.3$ \\
Saliva lipid peroxidation $(\mathrm{nmol} \mathrm{MDA} / \mathrm{ml})$ & $0.49 \pm 0.29$ & $0.26 \pm 0.23^{*}$ \\
\hline
\end{tabular}

Data are mean \pm S.D. Statistical analyses were made by Student $t$-test. $* p<0.05$ significantly different from the control group.

MDA, malondialdehyde.

TABLE 3. Wilcoxon test results of epithelial, leucocyte, dysplastic cells, bacteria and yeast cells in saliva imprint samples between breast cancer patients and healthy controls.

\begin{tabular}{llcc}
\hline & & Control group $(n=11)$ & Breast cancer group * $(n=20)$ \\
\hline Epithelial cells & 1 & $54.5 \%(n=6)$ & $20 \%(n=4)$ \\
& 2 & $45.5 \%(n=5)$ & $80 \%(n=16)$ \\
Leucocytes & 0 & $36.4 \%(n=4)$ & $40 \%(n=8)$ \\
& 1 & $63.6 \%(n=7)$ & $15 \%(n=3)$ \\
Dysplastic cells & 0 & $0 \%$ & $45 \%(n=9)$ \\
& 1 & $100 \%(n=11)$ & $75 \%(n=15)$ \\
Bacteria & 1 & $0 \%$ & $25 \%(n=5)$ \\
Yeast cells & 2 & $27.3 \%(n=3)$ & $20 \%(n=4)$ \\
& 0 & $72.7 \%(n=8)$ & $80 \%(n=16)$ \\
& 1 & $100 \%(n=11)$ & $75 \%(n=15)$ \\
& 2 & $0 \%$ & $20 \%(n=4)$ \\
\end{tabular}

Wilcoxon signed-rank test was used to estimate the difference between groups.

$* p>0.05$, epithelial, leucocyte, dysplastic, bacteria and yeast cells were not significantly different in breast cancer patients. P4, P7, P12, P13 and P15 had dysplastic cells. P9, P16, P17, P19 had scarce yeast cells where P14 had many yeast cells. P represents the patient group; the numbers represent the subjects in the group.

$\begin{array}{lll}\text { Epithelial cell } & \text { 1: } 7-8 \text { cells (normal) } & \text { 2: } 15-20 \text { cells (more than normal) } \\ \text { Leucocyte } & \text { 0: No cell } & \text { 1: } 7-8 \text { cells (normal) } 2: 15-20 \text { cells (more than normal) } \\ \text { Dysplastic } & \text { 1: Present } & \text { 2: Not present } \\ \text { Bacteria } & \text { 1: Scarce } & \text { 2: Many } \\ \text { Yeast cell } & 0: \text { Not present } & \text { 1: Scarce } \quad 2: \text { Many }\end{array}$

saliva imprint samples of the control group had neither dysplastic cells nor yeast cells. However, dyplastic cells were observed in the saliva imprint samples of five patients with breast cancer $(\mathrm{P} 4$, P7, P12, P13 and P15) (Table 3, Fig. 2).
Moreover many yeast cells were detected in the saliva imprint sample of one patient (P14) and scarce yeast cells were observed in four patients with breast cancer (P9, P16, P17, P19) (Table 3).

In the control group, 7 subjects had leuco- 

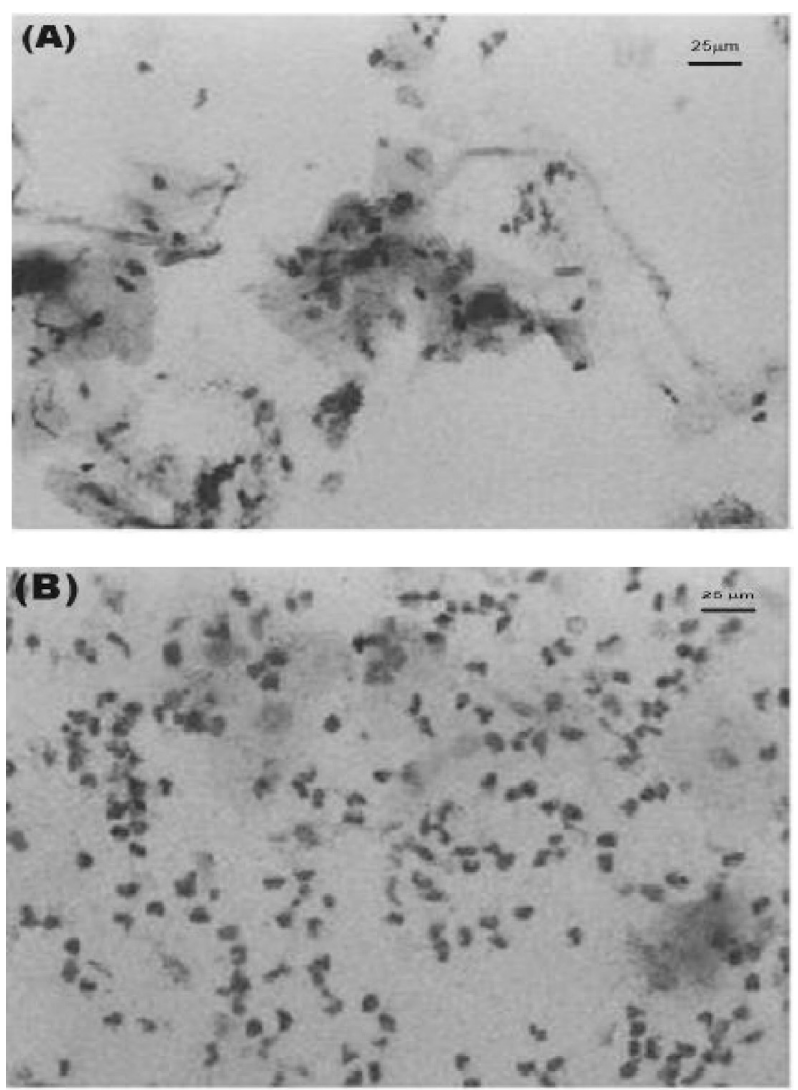

Fig. 1. Cytological examination of Giemsa stained saliva samples of (A) control (C2) and (B) breast cancer patient $(\mathrm{P} 4)$. Leucocytes were increased insignificantly in saliva of breast cancer patient. $\mathrm{C}$ and $\mathrm{P}$ represent control group and patient group respectively; the numbers represent the subjects in the group. (original magnification $\times 100$, scale bar $=25 \mu \mathrm{m}$ )

cytes in the normal range where 4 subjects had no leucocytes in their saliva imprint samples. On the other hand, 3 patients with breast cancer had leucocytes in the normal range where 9 patients had increased number of leucocytes in their saliva imprint samples (Table 3, Fig. 1).

The analysis of saliva proteins by SDS polyacrylamide gel electrophoresis revealed the noticeable differences between healthy controls and breast cancer patients (Fig. 3). The patients group showed the retarded mobility of the $66-\mathrm{kDa}$ proteins and the increased proteins of about $36 \mathrm{kDa}$.

\section{Discussion}

Screening for breast cancer has been shown

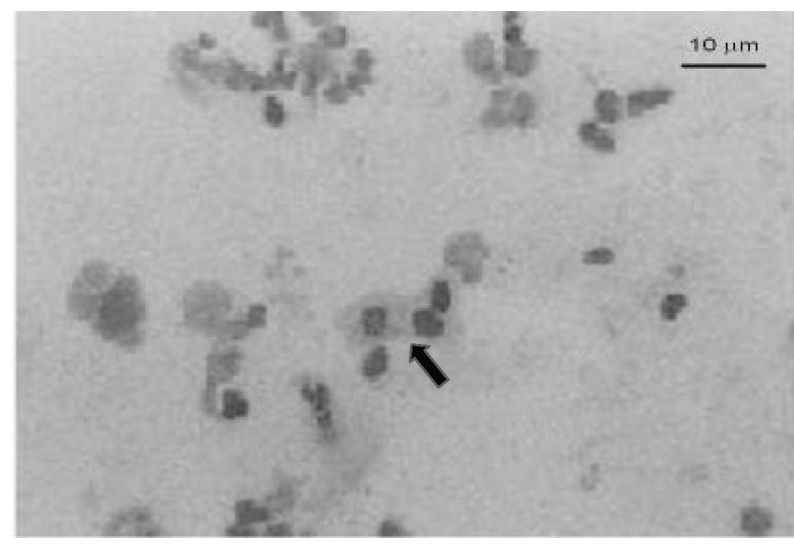

Fig. 2. Cytological examination of Giemsa stained saliva sample of breast cancer patient (P4) showed the presence of dysplastic cells (black arrow). P represents the patient group; the numbers represent the subjects in the group.(original magnification $\times 400$, scale bar $=10 \mu \mathrm{m})$

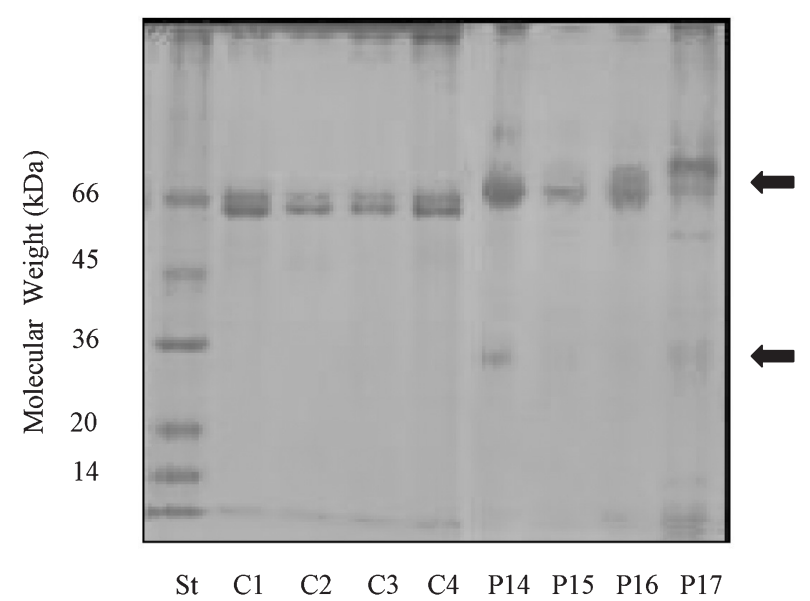

Fig. 3. Electrophoretic pattern of some saliva samples.

St: Low Molecular Weight Standard (SDS7, Sigma); C1,C2,C3,C4: Control subjects; P14, P15, P16, P17: Breast cancer patients. Their characteristics are given in Table 1. The patients group showed an increased set of bands that correspond to the molecular weight region above $66 \mathrm{kDa}$ and in $36 \mathrm{kDa}$ (black arrow).

to reduce breast cancer mortality (Bigler et al. 2002). Salivary biomarkers have been identified that may provide diagnostic information about a variety of cancers and other diseases. In particular, proof-of-principle has been demonstrated for sali- 
vary c-erbB-2, whose elevation has been shown to correlate strongly with breast malignancy in women (Strecfus and Bigler 2005).

As the principal biological initiator of blood coagulation, TF is believed to play a critical role in thrombosis and thrombogenesis (Nemerson 1995; Marutsuka et al. 2005) and concentrations in several biological fluids correlate with different pathological conditions (Fareed et al. 1995). TF is expressed in a wide range of cancer cells and plays important roles in cancer progression and metastasis. Recently, the intracellular function of TF has been revealed to be involved in cancer invasion, independent of the blood coagulation pathway (Ueno et al. 2000). Ueno et al. (2000) showed an up-regulation of plasma TF concentration in breast cancer patients compared with controls. Moreover in their study, the concentration of plasma TF was associated with tissue TF expression in both tumour and stroma.

Saliva has long been recognized as having thromboplastic properties (Bellis and Scott 1933; Ersner et al. 1934; Glazko and Greenberg 1939; Noun-Eldin and Wilkonson 1957; Doku and Taylor 1962; Zacharski and Rosenstein 1979; Yarat et al. 2004). However, our study is the only one in the literature, which evaluated salivary TF activity in patients with breast cancer. Salivary TF activity of breast cancer patients did not change significantly when compared with the controls. This is relevant to the cytological examination of saliva samples where no differences were observed in salivary cells between breast cancer patients and the controls, since approximately $78 \%$ of salivary TF activity is attributed to cells found in saliva (Zacharski and Rosenstein 1979).

On the other hand, although statistically insignificant, TF activity was found to be increased compared with the control group. We may suppose that the results could be more significant if patients were with similar histological diagnoses and stages of carcinoma of the breast. Since patients with breast cancer were having adjuvant, neoadjuvant and palliative therapy, we assume that changed salivary TF activity can be due to these therapies. However, Auger and
Mackie (1988) investigated the effects of tamoxifen on blood coagulation in patients with clinically localized breast carcinoma. They reported that, tamoxifen did not induce significant changes in parameters of coagulation (antithrombin III, protein $\mathrm{C}$, fibrinopeptide $\mathrm{A}$ and in vitro monocyte procoagulant activity) to account for the reported thromboembolic events associated with this therapy. Therefore the increased TF activities in breast cancer patients may represent the net effects caused by cancer itself. However we believe that investigation of the effects of specific therapies on TF activity may illuminate this debate.

Total protein, LPO levels and $\mathrm{pH}$ values of breast cancer patients were significantly lower than that of healthy controls. Hannig et al. (2006) compared the relative amount of low molecular weight salivary proteins in patients with head and neck tumours treated with radiotherapy and healthy subjects. They found significantly reduced fraction of acidic proline-rich proteins compared with non-irradiated healthy subjects. On the other hand, Makkonen et al. (1986) analyzed the radiation-induced changes in the flow rate and protein composition of stimulated whole saliva in eleven patients treated for malignant conditions of the head and neck. They observed unusually high salivary concentrations of albumin, lactoferrin, lysozyme, salivary peroxidase, myeloperoxidase, and total protein during the therapy, but most values slowly returned to pretreatment levels after cessation of radiation. They concluded that the observed qualitative changes in whole saliva components were net effects caused by the cancer itself, radiation therapy given, systemic diseases, or medications, as well as mucosal inflammations.

The observation of electrophoregrams of total saliva samples of patients with cancer showed notable differences in some protein bands, compared with the control group (Fig. 3). Under our experimental conditions, the saliva samples of patients group showed the retarded mobility of the $66-\mathrm{kDa}$ proteins and the increased proteins of about $36 \mathrm{kDa}$, which led us to infer that the proteins of $66 \mathrm{kDa}$ can undergo a process that causes an increase in their molecular mass or 
changes in their synthesis or post-translational changes. Since up-regulation of plasma TF concentration has been shown in breast cancer patients, increased bands in the saliva of breast cancer patients, may correspond to increased TF since TF is a $47 \mathrm{kDa}$ glycoprotein (Lopes-Bezerra and Filler 2003).

Coagulation disorders have been associated with the use of chemotherapeutic drugs. Walsh et al. (1992) suggested that membrane alterations, which occur following treatment with DNA/RNA intercalating drugs such as cisplatin and adriamycin (doxorubicin), may result in a highly active form of monocyte/macrophage $\mathrm{TF}$, thereby contributing to the complications caused by activated coagulation. Accordingly in the present study, patients who received epirubicin (P15 and P17) which is an antineoplastic agent derived from doxorubicin, showed an increased set of bands in the molecular weight region about $36 \mathrm{kDa}$, that may correspond to increased TF (Fig. 3). Moreover these patients had periodontal disease which is chronic Gram-negative infection, and secondary Gram-negative infections were reported to contribute to the procoagulant potential of these cytotoxic drugs (Walsh et al. 1992).

On the other hand, zinc- $\alpha 2$-glycoprotein is a $41-\mathrm{kDa}$ protein present in saliva, and is secreted by a variety of normal and malignant epithelial cells and overexpression by tumors has been implicated in cancer cachexia (Schenkels et al. 1995; Hale 2002). Therefore increased bands may also correspond to increased zinc$\alpha 2$-glycoprotein in breast cancer patients. However, detailed analysis of the bands is necessary to decide on the exact protein.

Our results suggest no significant differences between breast cancer patients and healthy controls regarding epithelial cells, leucocytes, bacteria, dysplastic cells, and yeast cells. However, dysplastic cells and yeast cells were present (Table 3, Fig. 2) and leucocytes were increased in saliva imprint samples of breast cancer patients (Fig. 1).

Cellular oxidants, called reactive oxygen species (ROS), are constantly produced in animal and human cells. Lipid peroxidation is probably the most extensively investigated free radical- induced process. Data support the notion that increased formation of ROS may play an important role in carcinogenesis, atherosclerosis, diabetes, emphysema, cataracts, and neurodegenerative diseases (Sodergren 2000; Salganik 2001). However, accumulating data suggest that ROS not only act as damaging entities but also may carry out important beneficial functions. ROS seem to be mediators or triggers of protective mechanisms, such as apoptosis, phagocytosis, and detoxification reactions. Among these mechanisms, apoptosis, which eliminates precancerous and cancerous cells, is particularly important (Salganik 2001). Moreover, Gago-Dominguez et al. (2005) suggested the possibility that decreased lipid peroxidation may be a mechanism responsible, at least in part, for the increased risk associated with several hormonal and nonhormonal risk factors for breast cancer. This may be one of the reasons for the decreased salivary lipid peroxidation observed in breast cancer patients in our study.

\section{Conclusion}

We conclude that patients with breast cancer present a significant reduction of total protein, $\mathrm{pH}$ and LPO levels. The patients group showed the retarded mobility of the $66-\mathrm{kDa}$ proteins and the increased proteins of about $36 \mathrm{kDa}$. Further studies investigating the effects of different types of chemotherapies including patients with the different stages of the disease are necessary.

\section{References}

Alturfan, A.A., Alturfan, E.E., Dariyerli, N., Zengin, E., Aytac, E., Yigit, G. \& Kokoglu, E. (2006) Investigation of tissue factor and other hemostatic profiles in experimental hypothyroidism. Endocrine, 30, 63-67.

Arana, C., Cutando, A., Ferrera, M.J., Gómez-Moreno, G., Worf, C.V., Bolaños, M.J., Escames, G. \& AcuñaCastroviejo, D. (2006) Parameters of oxidative stress in saliva from diabetic and parenteral drug addict patients. $J$. Oral Pathol. Med., 35, 554.

Auger, M.J. \& Mackie, M.J. (1988) Effects of tamoxifen on blood coagulation. Cancer, 1, 1316-1319.

Atay, Z. \& Topalidis, T. (1994) Cytodiagnostik der Serösen Höhlen. Atlas und Lehrbuch.Wolfgang Pabst verlag, Hannover.

Bellis, C. \& Scott, F.H. (1933) Saliva and blood coagulation. Proc. Soc. Exp. Biol. Med., 30, 1373.

Bigler, L.R., Streckfus, C.F., Copeland, L., Burns, R., Dai, X., 
Kuhn, M., Martin, P. \& Bigler, S.A.J. (2002) The potential use of saliva to detect recurrence of disease in women with breast carcinoma. Oral Pathol. Med., 31, 421-431.

Dawes, C. (1996) Factors influencing salivary flow rate and composition. In: Edgar WM, O'mualle DM (eds) Saliva and oral health. Thanet Press Limited, Margate, UK, pp. 27-41.

Doku, H.C. \& Taylor, R.G. (1962) Thromboplastin generation by saliva. Oral Surg. Oral Med. Oral Pathol., 15, 1295-1301.

Emekli-Alturfan, E., Kasikci, E. \& Yarat, A. (2007) Tissue factor activities of streptozotocin induced diabetic rat tissues and the effect of peanut consumption. Diabetes Metab. Res. Rev., 23, 653-658.

Epstein, J.B., Robertson, M., Emerton, S., Phillips, N. \& Stevenson-Moore, P. (2001) Quality of life and oral function in patients treated with radiation therapy for head and neck cancer. Head Neck, 23, 389-398.

Ersner, M.S., Myers, D. \& Ersner, W. (1934) A clinical and experimental study of the action of saliva on blood coagulation and wound healing in surgery of the oral cavity and throat. Ann. Otol. Rhinol. Laryngol., 43, 114.

Fareed, J., Callas, D.D., Hoppensteadt, D. \& Bermes, E.W. Jr. (1995) Tissue factor antigen levels in various biological fluids. Blood Coag. Fibrinol., 6, 32-36.

Gago-Dominguez, M., Castelao, E., Pike, M.C., Sevanian, A. \& Robert, W. (2005) Role of Lipid Peroxidation in the Epidemiology and Prevention of Breast Cancer. Cancer Epidemiol. Biomarkers Prev., 14, 2829-2839.

Glazko, A.J. \& Greenberg, D.M. (1939) The mechanism of the action of saliva in blood coagulation. Am. J. Physiol., 125, 108.

Hale, L.P. (2002) Zinc- $\alpha 2$-glycoprotein Regulates Melanin Production by Normal and Malignant Melanocytes. $J$. Invest. Dermat., 119, 464-470.

Hannig, M., Dounis, E., Henning, T., Apitz, N. \& Stößer, L. (2006) Does irradiation affect the protein composition of saliva? Journal Clinical Oral Investigations, 10, 61-65.

Ingram, G.I.C. \& Hills, M. (1976) Reference method for the one stage prothrombin time test on human blood. Thromb. Haemostas., 36, 237-238.

Laemmli, U.K. (1970) Cleavage of structural proteins during the assembly of the head of bacteriophage T4. Nature, 227, 680-685.

Lopes-Bezerra, L.M. \& Filler, S.G. (2003) Endothelial cells, tissue factor and infectious diseases. Braz. J. Med. Biol. Res., 36, 987-991.

Lowry, O.H., Rosebrough, W.I., Forr, A.L. \& Randal, R.J. (1951) Protein measurement with the folin phenol reagent. J. Biol. Chem., 193, 265-275.

Makkonen, T.A., Tenovuo, J., Vilja, P. \& Heimdahl, A. (1986) Changes in the protein composition of whole saliva during radiotherapy in patients with oral or pharyngeal cancer. Oral Surg. Oral Med. Oral Pathol., 62, 270-275.

Mandel, I.D. (1987) The function of saliva. J. Dent. Res., 66, 623-627.

Marutsuka, K., Hatakeyama, K., Yamashita, A. \& Asada, Y. (2005) Role of thrombogenic factors in the development of atherosclerosis. J. Atheroscler. Thromb., 12, 1-8.

Miller, C.S., Epstein, J.B., Hall, E.H. \& Sirois, D. (2001)
Changing oral care needs in the United States: the continuing need for oral medicine. Oral Surg. Oral Med. Oral Pathol. Oral Radiol. Endod., 91, 34-44.

National Institute of Health Consensus Development Conference on Oral Complications of Cancer Therapies (1990) Diagnosis, Prevention, and Treatment. Bethesda, Maryland, April 17-19, 1989. NCI Monogr; 9, 1-184.

Nemerson, Y. (1995) Tissue factor: then and now. Thromb. Haemost., 74, 180-184.

Noun-Eldin, F. \& Wilkinson, J.F. (1957) The blood clotting factors in human saliva. J. Physiol., 136, 324.

Price, G.C., Thompson, S.A. \& Kam, P.C.A. (2004) Tissue factor and tissue factor pathway inhibitor. Anaesthesia, 59, 483-492.

Rauch, U. \& Nemerson, Y. (2000) Circulating tissue factor and thrombosis. Curr. Opin. Hematol., 7, 273-277.

Salganik, R.I. (2001) The benefits and hazards of antioxidants: controlling apoptosis and other protective mechanisms in cancer patients and the human population. J. Am. Coll. Nutr., 20, 473-475.

Schenkels, L.C., Veerman, E.C. \& Nieuw Amerongen, A.V. (1995) Biochemical composition of human saliva in relation to other mucosal fluids. Crit. Rev. Oral Biol. Med., 6, 161-175.

Sodergren, E. (2000) Lipid peroxidation in vivo. Evaluation and application of methods for measurement. Uppsala: Acta Universitatis Upsaliensis. Comprehensive Summaries of Uppsala Dissertations from the Faculty of Medicine, pp. 949.

Sonis, S.T., Oster, G., Fuchs, H., Bellm, L., Bradford, W.Z., Edelsberg, J., Hayden, V., Eilers, J., Epstein, J.B., LeVeque, F.G., Miller, C., Peterson, D.E., Schubert, M.M., Spijkervet, F.K. \& Horowitz, M. (2001) Oral mucositis and the clinical and economic outcomes of hematopoietic stem-cell transplantation. J. Clin. Oncol., 19, 2201-2205.

Streckfus, C. \& Bigler, L. (2005) The use of soluble, salivary c-erbB-2 for the detection and post-operative follow-up of breast cancer in women: the results of a five-year translational research study. Adv. Dent. Res., 18, 17-24.

Ueno, T., Toi, M., Koike, M., Nakamura, S. \& Tominaga, T. (2000) Tissue factor expression in breast cancer tissues: its correlation with prognosis and plasma concentration. Br. J. Cancer, 83, 164-170.

Versteeg, H.H., Spek, C.A., Peppelenbosch, M.P. \& Richel, D.J. (2004) Tissue factor and cancer metastasis: the role of intracellular and extracellular signaling pathways. Mol. Med., 10, 6-11.

Walsh, J., Wheeler, H.R. \& Geczy, C.L. (1992) Modulation of tissue factor on human monocytes by cisplatin and adriamycin. Br. J. Haematol., 81, 480-488.

WHO (2006) Cancer. Fact sheet No. 297.

Yagi, K. (1984) Assay for blood plasma or serum. Methods Enzymol., 105, 328-337.

Yarat, A., Tunalı, T., Pisiriciler, R., Akyuz, S., Ipbuker, A. \& Emekli, N. (2004) Salivary thromboplastic activity in diabetics and healthy controls. Clin. Oral Invest., 8, 36-39.

Zacharski, L.R. \& Rosenstein, R. (1979) Reduction of salivary tissue factor (Thromboplastin) activity by warfarin therapy. Blood, 53, 366-374. 